\title{
A Systematic Literature Review of Pop Activism in Chinese Visual Culture
}

\author{
Chenyi $\mathrm{Wu}^{1, *}$ \\ ${ }^{1}$ Department of Theatre and Film, Theatre and Film Directing, Communication University of China, NO.1 \\ Dingfuzhuang East Street, Chaoyang District, Beijing, P.R. China \\ *Corresponding author email: larry071016@cuc.com
}

\begin{abstract}
The objective of this research was to examine development and effects of Pop Activism in China ranging from dadaism to online expression. To achieve this objective, this paper were divided to three aspects to analyze Pop Activism, the development of Pop Art in China, the communication characteristics of Pop Activism and how Pop Activism affecting Chinese cyberpolitics. With the development of technology, the way of video-making and image-making have became easier than before that every netizen can produce memes, micro-images and auto-tuned remix videos by themselves. Accordingly, online expression gradually became a crucial part of visual culture in China. These kind of ways of expression are deeply engage in Chinese cyberpolitics, and it is a mean of moblization. The first part of this essay introduced the development of popart in China and how western art movement, such as Dadaism and Pop Art, affecting chinese art movement. The second part discussed the communicaiton characteristics of Pop Activism, deconstructing the positions of other communities and maintaining the emotional connection within the communities. The third part explain the relationship between "cyber-nationalism" and Pop Activism.
\end{abstract}

Keywords: Pop Art, Chinese Cyberpolitics, Visual Culture.

\section{INTRODUCTION}

Pop Activism is a term coined by Rongbin Han who is a scholar study in Chinese cyberpolitics. It is an interdisciplinary term that including politics, art as well as communication. This term is used to describe the feature of Chinese online expression, and in terms of visual expression of Pop Activism, it includes emojis, auto-tuned remix video, and bullet comments. The genealogy of visual expression of Pop Activism can be traced back to Dadaism. Dadaism was an art movement of the European avant-garde in the early 20th century, and it strongly promoted the birth of pop art. "Pop Art" is a kind of contemporary art that originated in Europe and the United States after World War II, which is based on consumerism culture and was introduced to China after the end of the "Cultural Revolution". After that period of time, Chinese young artists launched an art movement which is the "85 Art Movement", and it was strongly influenced by Pop Art and other post-modern arts.

The "Political Pop" and "Cynical Realism" with Chinese characteristics emerged in the "85 Art
Movement". With the attitude of "non-heroic confrontation", the"Political Pop" and "Cynical Realism" parodies "theological politics" and deconstructs the suffering of "Cultural Revolution". After the disillusionment of Utopianism, it is the reflection of the general "depoliticization" mentality in Chinese society. With the advent of the internet as well as social media, the way of visual expression became increasingly easier than before, and this change democratize the right of expression. Accordingly, the strategies of expression in art were absorbed by netizens to express themselves, forming "pop activism". The so-call "pop activism" as a strategy of political mobilization and the speaking strategy from netizens make a difference in Chinese cyberpolitics. It is not just used to deconstruct official political discourse, but also used by pro-regime netizens to strengthen the ideology of the country.

This essay will discuss the development of pop art in China, dissecting "pop activism" which is the new strategy of expression in social media, and clarify the characteristics of this form of expression, teasing out the interactions between online expression and cyberpolitics. 


\section{THE DEVELOPMENT OF POP ART}

In 1956 Richart Hamilton exhibited his painting which is viewed as the representative artwork of pop art ---- Just what is it that makes today's homes so different, so appealing? In this painting, a man with a toned physique standing in the center of the living room was posing a gesture to show his figure and he held a tennis racket with an English word 'pop' to cover the private part. Interestingly, all of the images in this painting come from advertisements of mass media, such as Ladies' Home Journal, Young Love Magazine, The Journal of Commerce, Tomorrow's Man Magazine, and so on. It's believed by many that the term 'pop art' could be traced back to the critic Lowrance Alloway's article The Arts and the Mass Media. The most common feature of pop art is that the material of artworks comes from commonplace objects, such as comic strips, road signs, soup cans, advertisements, and so on. Lots of artists use these found objects to create their artworks, all of these artworks with cynical attitudes and make people have a reflection of that consumer society, such as Roy Lichtenstein, Robert Rauschenberg, and Andy Warhol. In the 1960s, the counterculture movement was in full swing, all of the left-wing youngsters advocated to overthrow authorities, outdated social norms and prepared to subvert the culture created by the last generation, hence the pop art which is humorous, anti-classical, and anti-authoritative, has become popular at the era.

\section{1." Political pop "----The combination of pop art and the images of political propaganda}

The Cultural Revolution was a political movement with great influence on China, which forms a special visual culture in China. During the Cultural Revolution, a wealth of political propaganda posters were produced by painters. All of these propaganda posters have figures which were painted by stiff, powerful lines and have giant captions which were used to propagate political slogans. Accordingly, when the consumer culture, such as advertisements, magazines, celebrities' photos, TV programs, and so forth were pervasive in western societies, the political posters were pervasive in Chinese society. So these images became the mass visual culture of China as opposed to commercials.

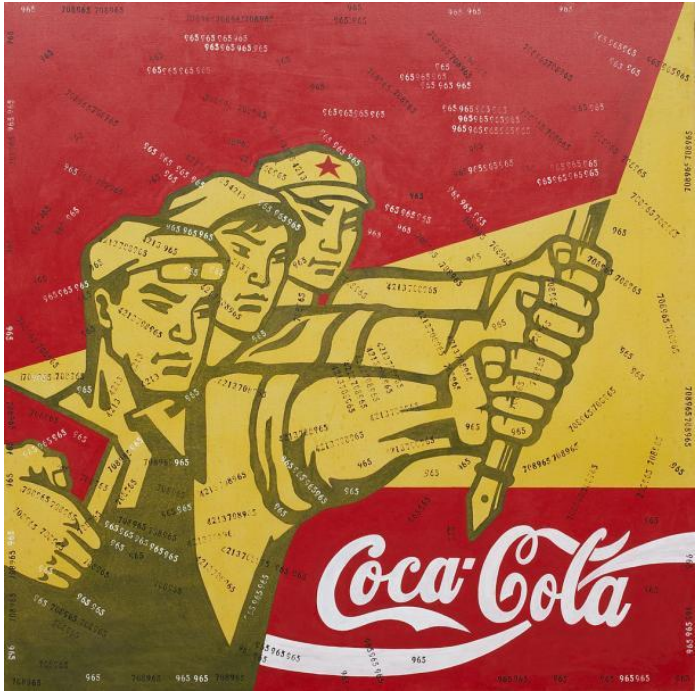

Figure 1 The Great Critics, Wang Guangyi [1]

After the Cultural Revolution, Chinese economic policies began to change. President Deng decided to impose the reform and opening-up policy. The strict cultural environment became loosening. A variety of art was burst at that time. That is the cultural background of the "85 Art Movement". Influenced by western modern art, Chinese artists in the post-Cultural Revolution era began to create art that responded to this special reality of China. Cynical realism, gaudy art, political pop had gradually risen at that time. Inspired by Western pop art, artist Wang Guangyi created the Great Criticism series by juxtaposing political propaganda images during the Cultural Revolution with commercial symbols that flooded into China rapidly after the reform and opening up. Artist Wang Guangyi creates an interesting tension by juxtaposing a revolutionary, anti-consumerist image with consumerist commercial symbols. The two popular images of mass culture have similar characteristics of communication, and the logic of political authority and capital forms an interesting joint here. XianTing Li argued that "political pop trend in the early 90s pop tunes of MAO Zedong's " red sun " songs of the rage, all reflects a complex social mentality. In Political Pop, " MAO complex " is not only a nostalgic mood which Chinese people were difficult to get rid of but also contains the meaning that using the 'god'(MAO Zedong) of Chinese people in past 30 years to mock the reality of now. More importantly, this kind of ridicule marks a unique way formed in the contemporary Chinese cultural situation, that is, the former gods and other political images, through popular and vulgar language transformation, have lost their former sanctity and solemnity"[2]. After political pop, such a non-heroic posture gradually formed a kind of widespread cynicism, this period also gave birth to cynical realism in the arts. Artists such as Fang Lijun, Yue Minjun, Zeng Fanzhi, create lots of exaggerated expressions [3]. A cynical mood diffuses in the pictures. Whether those skinheads look dull painted by Fang Lijun, guffawed youth, Yue 
Minjun painted, or the youngsters who wear masks painted by Zeng Fanzhi, they all express a kind of the loss of "face". The vivid face of people became a face that merely leave exaggerated expressions or personas. However, in the paintings of cynicism, the subjective emotion symbolized by eyes disappeared under the exaggerated "persona". Such non-heroic cynicism forms a solid mask on the hearts of the people.

Entering the 21 st century Internet era, Chinese society has entered a new field of public discussion and opinion. The gradual rise of online forums and social media has provided a large number of Chinese netizens with voice channels. The discourse power of public opinion was gradually decentralized, and the public discourse once dominated by the power of the media was decentralized to every Internet user who speaks in the field of public opinion. As a result, a kind of populist discourse was gradually rising in the field of public opinion. At the beginning of the reform and opening-up policy period, China's new left scholar Wang Hui called the "depoliticize" period, mainly embodied in the decline of political campaingns[4]. The political leaders no longer mentioned communism value, conversely they used the neo-liberal value in lieu of communism value which is a value underlining the free market economy. The value of the cultural revolution, a political consensus gradually recession became "hollowing out" as Chen Chun said. But Chen Chun goes further in his article: "This does not mean, however, that China does not have any chance of returning to 'totalitarianism'. The hollowing out of political and cultural structure and social organization structure after such 'depoliticization ' is a favorable condition for 're-politicization ' or even 'extreme politicization ' "[5]. This kind of populism was a kind of rebellion against official discourse mixed with cynicism in the first decade of the Chinese Internet, but after 2014, it has gradually been transformed into a political force mixed with populism, cynicism, and radicalism. The concentrated network expression forms during this period inherited the form and nihilism of Pop art and Dada and formed a special network visual culture, which is the "Pop Activism".

\section{TWO MAIN RHETORICAL STRATEGIES OF POP ACTIVISM PERSONATE AND PARODY}

In the development of the internet in China, with the rise of forums, video websites, social media, and other public speech Spaces and the popularization of picture editing and video editing technologies, netizens have gained the power and expression space to tamper with and reproduce public images in the Internet world. In the era of globalization, influenced by the animation culture of Japan and rage Comics of the United States, Chinese netizens gradually began to use these visual styles, which are quite popular in global pop culture, as means of expression. At the same time, in the field of political speech, such subcultural vision, as an expression with pop style, is used by netizens to deconstruct some ideological propaganda and political discourse. In 2009, for example, the Chinese government carried out Green Dam Software, a content censorship software that filters pornographic and politically sensitive online information. This incident aroused great dissatisfaction from the animation fans in China, so they took the initiative to create the image of Green Dam Lady to mock Green Dam software, turning the software into a female character, which is a process of personate, to express their dissatisfaction with the political censorship playfully. On the Tianya forum, some netizens also created the video program "The Emperor Looks Happy" to mock the social reality that was intentionally blocked from official News reports by making a parody of China Central Television's Evening News.

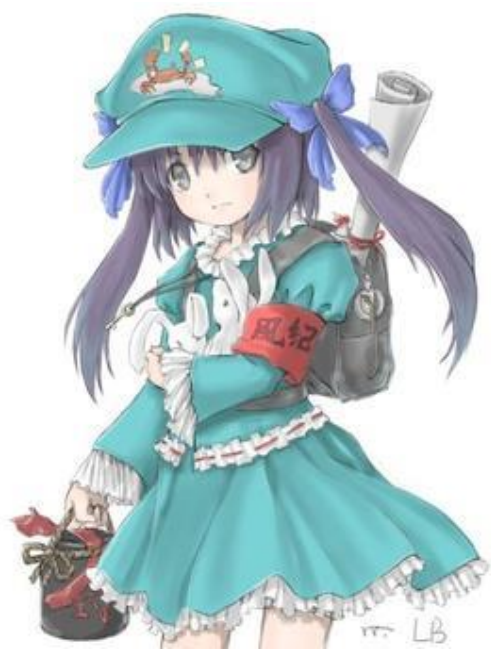

Figure 2 Green Dam Lady [6]

Here, we can see two visual rhetorical strategies of Pop activism: personate and parody. Cute culture originated from a large number of cute female cartoon characters in Animation, Comics, and Game (ACG) in Japan. Japanese Animation culture has formed a large number of fans in the process of spreading in China, and Animation culture has gradually become an important youth subculture phenomenon. We can see that in a "depoliticized" neoliberal Chinese society, young people have lost the strong communist value belief formed in the "politicized" Chinese society before 1979 so that they no longer trust the old political propaganda discourses produced by the government. Before 2014, China's official political propaganda strategy was still in its basic stage, and youth culture had not been incorporated into ideological propaganda strategies only through the education of history, official reports, and censorship. Thus, at this stage, the online anime fan base will release their dissatisfaction with the current political ideology by creating a cute character of the 
censorship system. Some of the Chinese scholars call it - cute politics. In the process of transforming the censorship system into a cute cartoon female character, the seriousness and authority of information censorship are dissipated and become a role identification with sexual implication, which is a deconstruction of political discourse. At the same time, such a deconstruction also allows netizens to reverse the power relationship in public space. Authority becomes a sexualized female character that can be designed and manipulated, and the creation of a series of music and pictures for this female image becomes a game within the group of animation fans. But, most of the studies about cute politics in China neglect the early stage of cute politics, which is cute politics as a form of protest. For instance, in the essay about cute politics from Ma Chuan and Sun Niu, they argue that the earliest works of cute politics are the comic strip Where does President Xi's time go, What makes a leader, and Year Hare Affair[7]. But actually, these comic strips and animations are created to support the official propaganda and to build up the positive image of the president as well as the positive narrative of history. As a matter of fact, if we burrow into the history of the Chinese internet we will find that in the beginning when the cute politics were rising, it is a way that the youngsters express their dissatisfaction with the authority.

Parody is another more common strategy of pop activism. Through parody of official words and images, the seriousness of official images is eliminated. At the same time, this strategy is also more aggressive. In the parody of China Central Television's Evening News, netizens expose the hypocrisy in News reports and also call some exaggerated News reports praised by netizens as the object of ridicule. Through parody, netizens through mock against serious and false political discourse hegemony, such as Wang Guangyi in the "great criticism" of political propaganda parodying deconstruction cultural revolution political image, Tian Ya Forums on the Internet users also deconstructs the parody of the way the Chinese authoritative news reports, this is a continuation of a pop trend. In his book Wired Power: Chinese Netizens in Action, Yang Guobin warmly praises netizens' creativity and humorous spirit: "Parody is as old as human civilization, but it has never have a renaissance as it does in China's cyberspace today. " Everything imaginable, especially those related to the rich and powerful, is subject to parody and mockery in Chinese cyberspace"[8]. Here we can say that the means of art are not limited to the traditional art field of oil painting and printmaking. The methods and thoughts of pop art have been popularized among netizens, and the public has turned the methods of pop art into an "action", a kind of public participation.

But interestingly, when we observe the current internet politics in China, we will find that the use of a series of visual rhetorical strategies of Pop activism seems to be greatly different from the past, or in other words, completely opposite. Cute figures have turned into online nationalist propaganda, like "Year Hare Affair", with parodies directed at liberal intellectuals critical of China and the United States. In the following article, this paper will discuss how the use of Internet memes in the online nationalist movement "Emperor Bar Go to war" has become an effective mobilization strategy, and how the visual rhetoric strategy of cute has been adopted by the authorities into a reconstruction of the value of nationalism.

\section{THE RISE OF CYBER NATIONALISM -- THE FLIP SIDE OF POP ACTIVISM}

Entering the Web 2.0 stage, the number of Netizens in China's Internet space has further expanded, and the netizen community has gradually formed a populist atmosphere in various Internet forums in China. Baidu Tieba(The online community integrated with Baidu search engine), based on the fans of former football player Li Yi, has become the online community with the largest number of netizens in China. Unlike the cynical culture prevalent in Tianya Forum, Baidu Tieba's netizens tend to have strong nationalist sentiment, which is related to its initial group composition. The fans of China's national football team are mainly male with strong patriotic tendencies. And that form Diao $\mathrm{Si}$ culture, which means the culture of the loser. Meanwhile, within the Animation fans group, Year Hare Affair, a patriotic cartoon, has gradually become a popular film and television work among young people. We can vaguely see that after President Xi took office, Chinese society has gradually undergone a rectification process from reality to the Internet, which gradually formed the "re-subjectivism" of The political consciousness of Chinese netizens. The ideologies of Loser and the animation fans group were gradually integrated by cute figures, the protagonist of Year Hare Affair, and other cultural images.

In 2016, we saw the mobilizing power of online nationalism in the event of "Emperor bar going to war". Taiwan entertainer Zhou Ziyu has posted a video apology on Facebook after her display of waving the flag of the republic of China during a South Korean TV show sparked an outcry among Chinese netizens. However, this move has also aroused strong protests from Taiwanese about national identity. The controversy on the issue of activists on the Internet has aroused strong dissatisfaction from Chinese netizens, and Emperor Bar, as the online community with the highest number of netizens in China, has a strong mobilization force. They formed organized posting teams that dominated Facebook topics with memes mocking young Taiwanese for their political stance on "Taiwan independence" and the Chinese flag. This phenomenon is called "image-contesting visual activism" by Professors Zhou Kui and Miao Weishan[9]. 
Tang Hongfeng, a professor from Peking University, analyzed the use of emoticons in the "Emperor Bar for War" campaign in his article "Selfies, Moments of Friends and Emoticons" by means of analytical painting. She defines the campaign as follows: "Unlike previous online polemics, this is a war of images -- not primarily using words and words to argue and persuade, but using images to occupy the space of the opponent's speech, the so-called emoji war." Moreover, Professor Tang Hongfeng analyzed the characteristics of collage culture contained in the image form of emoticons. "PS culture has become the type of post-modern collage culture, and it is particularly good at grafting a fixed image into another completely unrelated environment -- often a contradictory environment, deconstructing the existing stable meaning of the image. Scholars often understand the meaning behind this kind of humor in this way, that is, to dissolve it with the mixture, resulting in the hollow of meaning, and this hollow comes from the game or disassembling of two (or even multiple) layers of meaning inside and outside, resulting in an ironic nihilism"[10].

Thus, we can find that Pop Activism as an expression strategy has some commons with populism. As the nihilism inherent in Pop Activism produces hollow meaning, it becomes the territory for ideology to strive for dominance. That, of course, also thanks to the communist party of China has long formed through history education in China on the Taiwan issue underlying political identity. Through careful analysis we will find that in the past, the Pop Action (above-mentioned parody and personate) is pointing to the problem of China's internal affairs, not on the Chinese national identity; that is to say, the intention of Chinese youth to mock at politics is based more on a repressed desire for entertainment than a firm political appeal and stance. The majority of Chinese netizens do not have a good political discussion atmosphere and political consciousness as in western society. We are in a "depoliticized" social environment as Wang Hui put it.

At present, in China's Internet, more and more official media, such as China Central Television's Evening News, Central Committee of the Communist Youth League, Global Times, and so on, gradually and flexibly mobilize youth groups through Pop Activism such as personate and parody, forming a pro-regime political atmosphere. But Jiangshan Jiao, a patriotic idol launched by the Central Committee of the Communist Youth League, has not worked [11]. Instead, it drew criticism from netizens, who posted the unequal treatment of Chinese women in society on Weibo to this female idol created by the government [12]. This phenomenon also stems from the injury to female medical workers during the epidemic period.

\section{CONCLUSION}

From Andy Warhol to Wang Guangyi, from Green Dam Lady to Jiangshan Jiao, we can see a clear development vein of Pop activism. Pop activism is the fusion of Pop culture and Parody culture, with persoate and parody as two main rhetorical styles. The expression strategy of Pop activism in visual culture is an art form that grassroots and netizens can use to express jokes and satire. Although this art form has no difference in political standpoint, it has the characteristics of populism, that is, this art form cannot be directly used by the authorities, as can be seen from Jiang Shanjiao's failure. At present, the populism of Chinese netizens still has the characteristic of deconstruct authority, which is also an idea inherent in the art form and expression strategy of pop activism. In the era of "depoliticization", re-politicization needs to find the political consensus formed by ideology through long-term historical education and cultural propaganda from the mass narration, which is mostly presented in the way of nationalism, so as to awaken a "controllable" political subject. But incidents like "Emperor Bar going to War "show the danger of this online nationalism, which has the potential to turn into a Cultural Revolution. Pop activism, as a rhetorical strategy, is different from the serious and passionate political expression during the Cultural Revolution, but it has the same carnival attribute because such entertainment-oriented characteristics are rooted in grassroots culture. So, how to master and make good use of this narrative strategy will be a problem for both the Chinese government and the liberal intellectuals.

\section{REFERENCES} Information from : https://www.ames.cam.ac.uk/wang-guangyi-great-c riticism

[2] Li xianting, Consumption Image and Political Pop, 21 st Century, April 1993, p. 85.

[3] Xu Xiao, Beyond "Pop Activism"—_-From "Pop Activism" to "Multi-Activism",Captical Normal University

[4] Wang Hui.Depoliticized politics, multiple components of hegemony, and the eclipse of the Sixties. Sanlian Bookstore.

[5] Chen Chun.The Rebirth of Liberalism and political Virtue. New York: World Chinese Press, 2020, pp. 231-232.

[6] Wikipedia:Green Dam Lady:https://zh.wikipedia.org/wiki/\%E7\%BB\%BF \%E5\%9D\%9D\%E5\%A8\%98 
[7] Ma Chuan, Sun Niu. From "Cute politics " to "Anti-cute politics": the construction, reconstruction and reconstruction of contemporary youth's political subjectivity. no.6,2020 Chinese Youth Studies

[8] Guo Yangbin The Power of the Internet in China : Citizen Activism Online. Guangxi Normal University Press

[9] Zhou Kui, Miao Weishan"Image-contesting visual activism: A communication perspective of Chinese cyber nationalism".International press

[10] Tang Hongfeng,"Selfies, Moments of Friends and Emoticons". Literature and Culture, no.1, 2017 pp.46-56

[11] Fok Yit Wai, The short life of patriotic idol Jiangshan Jiao, Think China, 24 Feb 2020

[12] Josh Rudolph, Netizen Voices: Weibo users mock Communist Youth League's "visual idol", China Digital Times, Feb 192020. 